Tropical Journal of Pharmaceutical Research November 2015; 14 (11): 2077-2082

ISSN: $1596-5996$ (print); 1596-9827 (electronic)

(c) Pharmacotherapy Group, Faculty of Pharmacy, University of Benin, Benin City, 300001 Nigeria.

All rights reserved.

Available online at http://www.tjpr.org

Original Research Article

http://dx.doi.org/10.4314/tjpr.v14i11.18

\title{
Solid-Phase Extraction Combined with High Performance Liquid Chromatography-Diode Array Detector for Rapid Determination of Estrogens in Milk
}

\author{
Qinghua Yan ${ }^{1}$, Li Yang ${ }^{2}$ and Sufang $\mathrm{Li}^{3 *}$ \\ ${ }^{1}$ Department of Life Science and Technology, Xinxiang Medical University, ${ }^{2}$ Department of Experimental Center, Henan \\ Institute of Science and Technology, ${ }^{3}$ Department of Neurology, Third Affiliated Hospital, Xinxiang Medical College, Xinxiang \\ Henan 453003, PR China
}

*For correspondence: Email: yqh3499@163.com; Tel: +86-373-3831928

Received: 20 July 2015

Revised accepted: 12 October 2015

\begin{abstract}
Purpose: To develop a simple but effective method for the quantitative analysis of estrogens in milk. Methods: Solid-phase extraction method was employed for the extraction of the estrogen from milk and high performance liquid chromatography-diode array detector (HPLC-DAD) was used for the determination of estrogen.

Results: Optimal chromatographic conditions were achieved on an Eclipse XDB-C18 column at a flow rate of $0.8 \mathrm{~mL} / \mathrm{min}$ at room temperature. The products were monitored using a DAD detector set at 280 $\mathrm{nm}$. The retention time of the three main estrogens were $15 \mathrm{~min}$ with a gradient program of acetonitrile/water, from 0 to $3 \mathrm{~min}$, holding $35 \%$ acetonitrile; from 4 to $7 \mathrm{~min}$, ramped to $55 \%$ acetonitrile; from 8 to 20 min, maintained at $55 \%$ acetonitrile. The results showed that the calibration curve had good linearity within the concentration range of $0.5-8.0 \mu \mathrm{g} / \mathrm{mL}$ with correlation coefficient $\left(R^{2}\right)$ in the range of 0.9929-0.9936. The limit of detection was in the range of $0.025-0.045 \mu \mathrm{g} / \mathrm{mL}$ while mean recovery of estrogen from milk samples varied from 92.6 to $104.1 \%$. Satisfactory precision was obtained both for intra-assay (RSD, 1.8 to $4.4 \%$ ) and inter-assay (RSD, 2.0 to $4.7 \%$ ).

Conclusion: The proposed method is environmentally friendly, inexpensive and convenient, and should be helpful in analyzing estrogens in biological, environmental and food samples.
\end{abstract}

Keywords: Solid-phase extraction, Milk, Estrogens, High performance liquid chromatography-diode array detector

Tropical Journal of Pharmaceutical Research is indexed by Science Citation Index (SciSearch), Scopus, International Pharmaceutical Abstract, Chemical Abstracts, Embase, Index Copernicus, EBSCO, African Index Medicus, JournalSeek, Journal Citation Reports/Science Edition, Directory of Open Access Journals (DOAJ), African Journal Online, Bioline International, Open-J-Gate and Pharmacy Abstracts

\section{INTRODUCTION}

Estrogen is a kind of steroid hormone that can maintain female secondary sexual characteristics, with prominent compounds including natural estrone (E1), estradiol (E2), estriol (E3) (see Figure 1). With the improvement in living standards, the consumption of foods high in protein, such as milk, is growing rapidly. However, estrogen is used to promote animal growth, which causes a serious problem of estrogen being residual in milk and meat. These estrogens play a critical role in human carcinogenesis, such as breast, prostate, and ovarian cancer [1-3], and their special biological effect and potential hazard to human bodies has become another hot spot. Increased risk of breast cancer has been reported in women with high circulating and urinary estrogen levels, as well as in those exposed to increased estrogen levels over time [5]. Milk occupies a very important position in the human diet structure [4- 
6]. Therefore, safe milk source is essential. In fact milk was consumed about around 2000 years ago, but current intensive production systems are completely different from the traditional ones. Duo to the result of modern farming and animal breeding, today's milk comes from genetically modified cows which are mostly pregnant in most of the time of their lactation $[7,8]$. Thus, the estrogen residues in commercial milk show a sustained rise. There are substantial scientific efforts in progress to assess the levels of these compounds in various samples $[9,10]$. Therefore, to ensure the food safety and human health, it is essential to develop rapid, simple, and effective methods for the determination of estrogens in milk.

Estrogenic detection methods in wide use today include immunoassay [11], gas chromatographymass spectrometry (GC-MS) [12], liquid chromatography (LC), and liquid chromatography coupled with mass spectrometry (LC-MS), and thin layer chromatography [13-16]. Among them, immunoassays suffer from cross-reactions because of the similar structures of the estrogens. GC-MS and LC-MS were efficient in the separation and analysis of estrogens, however, the cost of samples testing is expensive, and the sample pre-treatment procedures are complicated. Therefore, the establishment of an accurate and efficient analytical method for the detection of estrogenic hormone is required.

Milk contains many kinds of macromolecular substances such as protein and fat. In addition to estrogens, they are generally present in samples at low concentrations and a simple separation and pre-concentration step is needed prior to their detection. Solid phase extraction is recognized as the most common sample pretreatment technique to enhance the concentration of a target in biological samples [17].

The aim of this work was to develop a simple, sensitive, inexpensive, and safe method for separation, pre-concentration, and determination of the estrogens in milk.

\section{EXPERIMENTAL}

\section{Apparatus}

The chromatographic system consisted of an online degasser, a six-way rotary valve sampler with a $25 \mu \mathrm{L}$ sample loop and a DAD system (Thermo Finnigan, MA, USA). An EclipseXDBC18 column $(250 \times 4.6 \mathrm{~mm}$ I.D; $5 \mu \mathrm{m})$ was used for the analysis, preceded by a C18 guard column (12.5 × $4.6 \mathrm{~mm}$ I.D.; $5 \mu \mathrm{m})$.

\section{Reagents and chemicals}

HPLC grade acetonitrile and methanol were obtained from Fisher Scientific. Three estrogens were purchased from Sigma. A $50 \mu \mathrm{g} / \mathrm{mL}$ mixed stock solution of the estrogens was prepared in methanol and stored at $4{ }^{\circ} \mathrm{C}$ in darkness. Then, $0.125,0.25,0.50,1.00,2.00,4.00$ and 8.00 $\mu \mathrm{g} / \mathrm{mL}$ of the mixed working solutions were prepared by diluting mixed stock solutions with mobile phase to create the calibration curves, and the working solutions were prepared freshly and filtered prior to analysis. Purified water with specific conductivity down to $0.055 \mu \mathrm{S} / \mathrm{cm}$ for the HPLC analysis was obtained with an Ultra-pure Water System (SG Ultra Clear system, Wasseraufbereitung und Regenerierstation GmbH, Germany).

\section{Milk samples and sample treatment}

Three randomly chosen different brand milk samples were collected from local markets in Xinxiang (China) and stored at $-20^{\circ} \mathrm{C}$.

Real milk samples, $10 \mathrm{~mL}$ were placed in a 50 $\mathrm{mL}$ eppendorf tube containing $10 \mathrm{~mL}$ of acetonitrile, the tubes were capped and vortexed. The tubes were treated with ultrasonic cleaner for $30 \mathrm{~min}$. After ultrasonication, the samples were centrifuged for $30 \mathrm{~min}$ at $2500 \mathrm{rpm}$ at room temperature.<smiles>CC12CCC3c4ccc(O)cc4CCC3C1CCC2=O</smiles><smiles></smiles><smiles>CC1C(O)C(O)CC2C3CCc4cc(O)ccc4C3CCC12C</smiles>

Figure 1: The chemical structure of estrone (E1), estradiol (E2) and estriol (E3) 
The acetonitrile layer was separated from the precipitate and subsequently, the precipitate was washed twice with acetonitrile, and the washed acetonitrile was collected. Transformation of the liquid in a nitrogen blowing instrument evaporated under a nitrogen stream at $85{ }^{\circ} \mathrm{C}$. The residue was re-dissolved in $1 \mathrm{~mL}$ of acetonitrile and transformed $5 \mathrm{~mL}$ eppendorf tube with acetonitrile. All solvents were filtered through a $0.45 \mu \mathrm{m}$ PTEE millipore prior to use. Meanwhile, blank solutions were analyzed in the same way.

\section{Chromatographic conditions}

Chromatographic column Eclipse XDB-C18 was used at $25{ }^{\circ} \mathrm{C}$. The sample injection volume was $10 \mu \mathrm{L}$ and the flow rate was $0.8 \mathrm{~mL} / \mathrm{min}$. For the HPLC-DAD method, retention time was controlled at $20 \mathrm{~min}$ and detection wavelength was operated at $280 \mathrm{~nm}$. The mobile phase consisted of acetonitrile (solvent $A$ ) and ultrapure water (solvent B) in HPLC experiment. The gradient conditions were as follows: from 0 to 3 min, holding $35 \%$ of $A$; from 4 to 7 min, ramped to $55 \%$ of $A$; and from 8 to $20 \mathrm{~min}$, left at $55 \%$ A.

\section{RESULTS}

\section{Mobile phase}

Acetonitrile-water as the mobile phase was chosen for the whole process of separation. The chromatograms of the three food estrogens are shown in Figure 2.

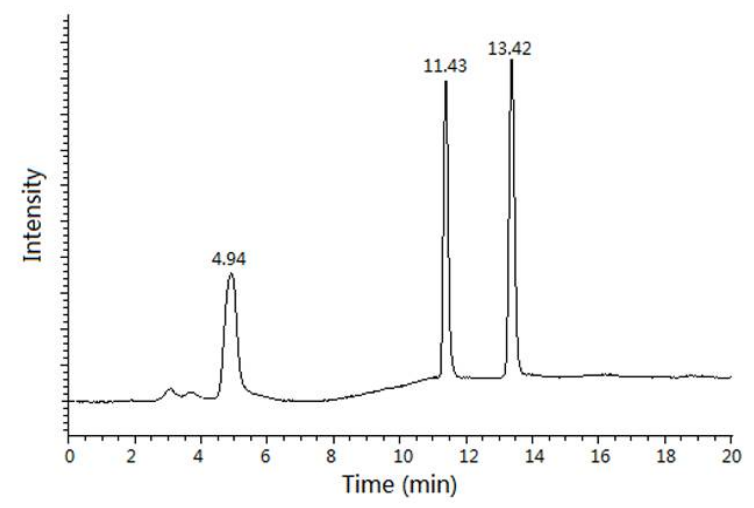

Figure 2: The chromatograms of estradiol (4.94 min), estrone (11.43 $\mathrm{min}$ ) and estradiol (13.42 $\mathrm{min})$ at 280 $\mathrm{nm}$

\section{Detection wavelength}

Estradiol, estrone and estradiol were scanned in the wavelength range of $200-600 \mathrm{~nm}$. The result displayed that the three estrogens had high sensitivity and low background interference at the wavelength of $280 \mathrm{~nm}$. Therefore, the detection wavelength was selected at $280 \mathrm{~nm}$. The UV absorption of the total wavelengths of three food estrogens was shown in Figure 3.

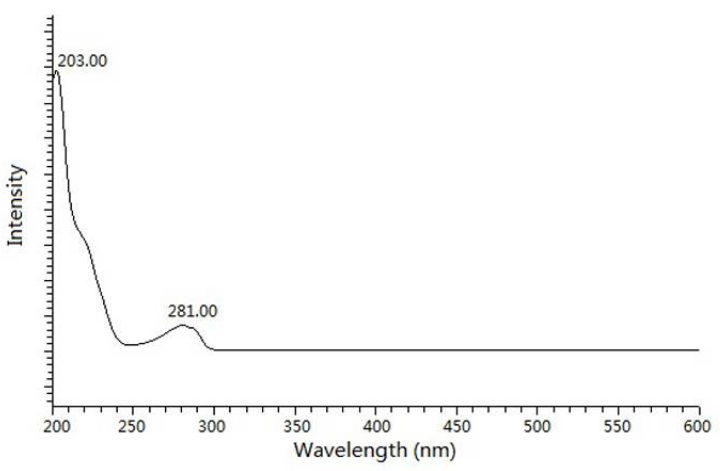

Figure 3: UV absorption of the total wavelengths of estradiol, estrone and estradiol

\section{Linear equation and correlation coefficient}

The linear equations of the three kinds of estrogens were established using the mixed working solutions of $0.125,0.25,0.50,1.00,2.00$, $4.00,8.00 \mu \mathrm{g} / \mathrm{mL}$. The working solutions were detected and peak areas were recorded with the above optimized chromatographic conditions, respectively. The linear equations of three kinds of estrogens were created according to peak areas versus working solution concentrations. Satisfactory correlation coefficients varied from 0.9929 to 0.9936 . The linear equations and correlation coefficients were listed in Table 1. The results indicate that the three estrogens have good linear relation in the concentration range of $0.5-8.0 \mu \mathrm{g} / \mathrm{mL}$.

\section{Limit of detection and of quantification, and precision}

The sensitivity of this analytical procedure was evaluated on the base of the limit of detection (LOD), which were calculated as the analytes content corresponding to signal-to-noise (S/N) ratio of 3 . The LOD was found in the range of $0.025-0.045 \mu \mathrm{g} / \mathrm{mL}$. The limit of quantification (LOQ) was determined as the analytes content corresponding to signal-to-noise ratio of 10 . LOQs of the three estrogens ranged from 0.083 to $0.15 \mu \mathrm{g} / \mathrm{mL}$. The LODs and LOQs of the three estrogens were indicated in Table 2. Estradiol and estriol had the lowest LOD values (0.025 and $0.045 \mu \mathrm{g} / \mathrm{mL}$ ) and the highest $\mathrm{LOQ}$ values (0.083 and $0.150 \mu \mathrm{g} / \mathrm{mL})$, respectively. 
Table 1: The linear equations and correlation coefficients of estrone, estradiol, estriol

\begin{tabular}{lcc}
\hline Analyte & Linear equation & Correlation coefficient $\left(\mathbf{R}^{2}\right)$ \\
\hline Estrone & $\mathrm{Y}=-85395.2+116126 \mathrm{X}$ & 0.9929 \\
Estradiol & $\mathrm{Y}=-85395.2+116126 \mathrm{X}$ & 0.9929 \\
Estriol & $\mathrm{Y}=-98682.2+118562 X$ & 0.9936 \\
\hline
\end{tabular}

The precision was calculated based on the relative standard deviation (RSD) for the determination of the three estrogens with a series of the working solutions (Table 2). The intra-assay precision was determined every $3 \mathrm{~h}$ and three replicates at each of three different concentration levels. Inter-assay precision was calculated with three replicates at three different concentration levels on four consecutive days. The RSDs obtained were indicated in Table 2 . Results revealed that satisfactory precision was both for intra-assay (RSDs from $1.8 \%$ to $4.4 \%$ ) and inter-assay (RSDs from $2.0 \%$ to $4.7 \%$ ).

\section{Performance of the established method}

To test the performance of the established method, the recovery experiment was performed through spiking milk samples 2. The concentration spiked was controlled according to
$80 \%$ base value, $100 \%$ base value and $120 \%$ base value with working solution, respectively. For each spiking stage, three replicate processes were made. The mean recoveries of the three estrogens in samples 2 were in the range of 92.67-104.1\% (Table 3).

\section{Application of proposed method to analysis of three estrogens in real samples}

To evaluate the feasibility of the method, three different kinds of milk samples were analyzed. Each sample was repeated three times. It can be found that sample 2 contains E1 $(0.143 \mu \mathrm{g} / \mathrm{mL})$, E2 $(0.124 \mu \mathrm{g} / \mathrm{mL})$, E3 $(0.242 \mu \mathrm{g} / \mathrm{mL})$. All estrogens were not detected in sample 1 and sample 3 . The chromatogram in the optimum HPLC conditions of sample 2 and the results are shown in Figure 4 and Table 4, respectively.

Table 2: The LOD and LOQ and precision of estrone, estradiol, estriol

\begin{tabular}{|c|c|c|c|c|}
\hline \multirow{2}{*}{ Analyte } & \multirow{2}{*}{$\operatorname{LOD}(\mu \mathrm{g} / \mathrm{mL})$} & \multirow{2}{*}{$\mathrm{LOQ}(\mu \mathrm{g} / \mathrm{mL})$} & \multicolumn{2}{|c|}{ Precision (RSD\%) } \\
\hline & & & intra-assay & intra-assay \\
\hline Estrone & 0.028 & 0.093 & 1.8 & 2.0 \\
\hline Estradiol & 0.025 & 0.093 & 2.3 & 2.8 \\
\hline Estriol & 0.045 & 0.150 & 2.3 & 2.8 \\
\hline
\end{tabular}

Table 3: Recovery data for three estrogens in milk samples

\begin{tabular}{lccccc}
\hline Analyte & $\begin{array}{c}\text { Base value } \\
(\mu \mathrm{g} / \mathrm{mL})\end{array}$ & $\begin{array}{c}\text { Quantity } \\
\text { added } \\
(\mu \mathrm{g} / \mathrm{mL})\end{array}$ & $\begin{array}{c}\text { Quantity } \\
\text { found } \\
(\mu \mathrm{g} / \mathrm{mL})\end{array}$ & Recovery (\%) & $\begin{array}{c}\text { Mean } \\
\text { recovery (\%) }\end{array}$ \\
\hline \multirow{3}{*}{ Estrone } & 0.143 & 0.114 & 0.247 & 91.5 & \\
& 0.143 & 0.143 & 0.277 & 93.4 & 92.6 \\
Estradiol & 0.143 & 0.172 & 0.303 & 92.8 & \\
& 0.124 & 0.099 & 0.221 & 97.9 & 98.9 \\
Estriol & 0.124 & 0.124 & 0.244 & 96.5 & \\
& 0.124 & 0.149 & 0.277 & 102.4 & 104.1 \\
\hline
\end{tabular}

Table 4: The results of three estrogens in three milk samples $(\mu \mathrm{g} / \mathrm{mL})$

\begin{tabular}{lccc}
\hline Analyte & Sample 1 & Sample 2 & Sample 3 \\
\hline Estrone & - & 0.143 & - \\
Estradiol & - & 0.124 & - \\
Estriol & - & 0.242 & - \\
\hline
\end{tabular}






Figure 4: The chromatograms of samples 2 in the optimum HPLC-DAD conditions.

\section{DISCUSSION}

The composition of milk is complex, in addition to water it also contains protein, fat and a variety of trace elements. In the study, according to the solubility of three estrogens, the mixture of diethyl ether and petroleum ether, acetonitrile, acetic acid, chloroform were used to treat samples. When chloroform, the mixture of diethyl ether and petroleum ether were used as the extraction solvents, the whole experiment was complicated, time-consuming and inefficient, the analytes were extremely easy emulsifications, the recovery rate was low and the reproducibility was poor. When acetic acid and acetonitrile solution of different concentrations were studied to extract the samples, the result showed that the samples were well extracted because of the low polar of acetonitrile. Therefore, acetonitrile was used as the extraction solvent and precipitant.

The effect of three different kinds of mobile phase system (methanol-water, methanol-0.01 $\mathrm{mol} / \mathrm{L}$ sodium dihydrogen phosphate, acetonitrilewater) was compared in the work. The result indicated that acetonitrile-water was the best as the mobile phase. Three estrogens could be separated completely, the peak shape was good, the retention time was moderate, target peak and other interfering peaks could be separated completely, the target peak had no trailing phenomenon and the peak shapes were symmetrical. Therefore, acetonitrile-water was chosen as the mobile phase.

On the optimization of mobile phase proportion, at first the proportion (50\%:50 \%) of acetonitrilewater was used to separate the sample. The retention time of estriol was very short while the retention time of the other two estrogens was too long. This, however, also showed that the polarity of the latter two substances was low. In order to reduce their retention time, the proportion of the acetonitrile was increased to reduce the polarity of mobile phase. At last, the gradient elution mode was used: from 0 to $3 \mathrm{~min}$, holding $35 \% \mathrm{~A}$; from 4 to $7 \mathrm{~min}$, ramped to $55 \%$ $\mathrm{A}$; from 8 to $20 \mathrm{~min}$, maintained $55 \% \mathrm{~A}$.

\section{CONCLUSION}

A rapid, convenient and efficient HPLC-DAD method for the simultaneous determination of estrone, estradiol, estriol in milk samples has been successfully developed. The precision, sensitivity and accuracy of the proposed method are satisfactory. The method is environmentallyfriendly, inexpensive, convenient, and should be suitable for monitoring estrogens in biological, environmental and food samples.

\section{ACKNOWLEDGEMENT}

The authors are grateful to Project of Scientific Research Fund of Xinxiang Medical University (no. 2013QN108).

\section{REFERENCES}

1. Xu X, Veenstra TD, Fox $S D$, Roman JM, Issaq HJ, Falk $R$, Saavedra JE, Keefer LK, Ziegler RG. Measuring fifteen endogenous estrogens simultaneously in human urine by high-performance liquid chromatography-mass spectrometry. Anal Chem 2005; 77: 6646-6654.

2. Xu X, Roman JM, Issaq HJ, Keefer LK, Veenstra TD, Ziegler RG. Quantitative measurement of endogenous estrogens and estrogen metabolites in human serum by liquid chromatography-tandem mass spectrometry. Anal Chem 2007; 79: 7813-7821.

3. Qin LQ, Wang PY, Kaneko T, Hoshi K, Sato A. Estrogen: one of the risk factors in milk of prostate cancer. Med Hypotheses 2004; 62: 133-142.

4. Hu YL, Fang YF, Li GK. Preparation and evaluation of a porous monolithic capillary column for micro extraction of estrogens from urine and milk samples online coupled to high-performance liquid chromatography. J Chromatogra A 2012; 1228: 205212.

5. Malekinejad $H$, Scherpenisse $P$, Bergwerff $A$ A. Naturally occurring estrogens in processed milk and in raw milk (from gestated cows). J Agric Food Chem 2006; 54 : 9785-9791.

6. Frédérique $C$, Jean-Philippe $A$, Julie $L A$, Fabrice $M$, François $A$ Bruno $L B$. Determintion of steroid hormones inmilk, egg, and meat samples. J Agric Food Chem 2008; 56: 3176-3184.

7. Maruyama K, Oshima T, Ohyama K. Exposure to exogenous estrogen through intake of commercial milk produced from pregnant cows. Pediatr Int 2010; 52(1): 33-38. 
8. Pape-Zambito DA, Roberts RF, Kensinger RS. Estrone and $\beta$-estradiol concentrations in pasteurized homogenized milk and commercial dairy products. J Dairy Sci 2010; 93(6):2533-2540.

9. Noppe H, Bizec BL, Verheyden K, De Brabander HF. Novel analytical methods of the determination of steroid hormones in edible matrices. Anal Chim Acta 2008; 611:1-16.

10. Wang S, Huang W, Fang GZ, He JX, Zhang Y. On-line coupling of solid-phase extraction to highperformance liquid chromatography for determination of estrogens in environment. Anal Chim Acta 2008; 606: 194-201.

11. Xin TB, Liang SX, Wang X, Li HF, Lin JM. Determination of estradiol in human serum using magnetic particlesbased chemiluminescence immunoassay. Anal Chim Acta 2008; 627: 277-284.

12. Hadef $Y$, Kaloustian J, Portugal H, Nicolay A. Multivariate optimization of a derivatisation procedure for the simultaneous determination of nine anabolic steroids by gas chromatography coupled with mass spectrometry. J Chromatogr A 2008; 1190: 278 -285.
13. Stafiej A, Pyrzynska K, Regan F. Determination of antiinflammatory drugs and estrogens in water by HPLC with UV detection. J Sep Sci 2007; 30: 985-991.

14. Labadie L, Hill EM. Analysis of estrogens in river sediments using liquid chromatography-electrospray ionization mass spectrometry: Comparison of tandem mass spectrometry with time-of-flight mass spectrometry. J Chromatogr A 2007; 1141: 174-181.

15. Li ZL, Wang S, Alice Lee N, Allan RD, Kennedy IR. Development of a solid-phase extraction-enzymelinked immunosorbent assay method for the determination of estrone in water. Anal Chim Acta 2004; 503: 171-177.

16. Wang $S$, Huang W, Fang GZ, He JX, Zhang Y. On-line coupling of solid-phase extraction to highperformance liquid chromatography for determination of estrogens in environment. Anal Chim Acta 2008; 606: 194-201.

17. Zhang J, Xie LC, Cong L, XU ZX, Qiao XG, Song JM. Separation and determination of trace environmental estrogen through molecularly imprinted solid phase extraction coupled to high performance liquid chromatography. J Environ Sci Heal A 2012; 47: 1889-1896. 